
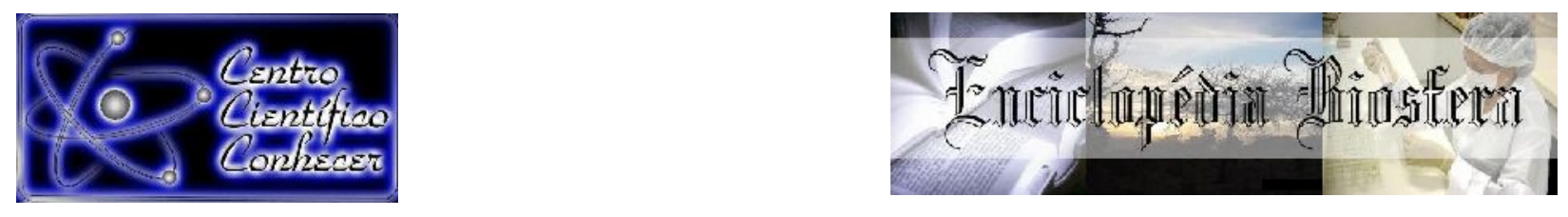

\title{
PLANTAS MEDICINAIS NOS QUINTAIS URBANOS DA COMUNIDADE ALTO DA CRUZ NO PITIÚ EM BATURITÉ-CE
}

Manoel Pereira da Silva Neto ${ }^{1}$, Maria Gorete Flores Salles ${ }^{2}$, Ciro de Miranda Pinto ${ }^{3}$,

Olienaide Ribeiro de Oliveira Pinto, Luzivone da Silveira do Nascimento Santos ${ }^{5}$

${ }^{1}$ Bacharel em Agronomia / Universidade da Integração Internacional da Lusofonia Afro-Brasileira (UNILAB), Redenção-CE, Brasil.

${ }^{2}$ Professora Doutora da UNILAB, Redenção-CE, Brasil. E-mail: gorete@unilab.edu.br

${ }^{3}$ Professor Doutor da UNILAB, Redenção-CE, Brasil.

${ }^{4}$ Professora no Mestrado Acadêmico em Sociobiodiversidade e Tecnologias

Sustentáveis da UNILAB, Redenção-CE, Brasil.

${ }^{5}$ Bacharel em Agronomia da UNILAB, Redenção-CE, Brasil.

Recebido em: 06/04/2019 - Aprovado em: 10/06/2019 - Publicado em: 30/06/2019 DOI: 10.18677/EnciBio_2019A102

\section{RESUMO}

A dificuldade no acesso à assistência de saúde por parte da população que não tem suas necessidades atendidas nas instituições de saúde faz com que usem plantas medicinais. Assim, o estudo teve o objetivo de conhecer sobre o uso de plantas medicinais na comunidade do Alto da Cruz no bairro Pitiú em área urbana do município de Baturité, Ceará, na cura de enfermidades. Para tal, foi aplicado de maio a outubro de 2017, um questionário estruturado quanti-qualitativo composto de 20 questões relacionadas ao uso das plantas medicinais e entrevistadas 50 pessoas de ambos os sexos com idade entre 18 a 84 anos. Os resultados mostraram que a maioria dos entrevistados foi de mulheres idosas, que adquiriram o conhecimento dos seus antepassados. Foram citadas 48 plantas medicinais distribuídas em 25 famílias, a Fabaceae e a Lamiaceae apresentaram o maior número de espécies. A camomila (Matricaria chamomilla) foi a espécie mais citada, 16 vezes $(21,3 \%)$, seguida do boldo (Peumus boldus) e erva doce (Pimpinela anisum) com 15 citações (20\%); erva cidreira (Melissa officinalis) e mastruz (Dysphania ambrosioides) 14 vezes $(18,7 \%)$. As partes da planta mais utilizadas foram as folhas $(49,3 \%)$, cascas $(13,4 \%)$, semente $(10,4 \%)$ e flor $(8,9 \%)$, sendo que a raiz, a entrecasca e o fruto tiveram igual citação de uso (6,0\%). A população da comunidade Alto da Cruz utiliza plantas medicinais para manter a saúde não só por tradição de uso que é bem forte na comunidade, mas também, em função das dificuldades financeiras para adquirir medicamentos alopáticos vendidos nas farmácias locais.

PALAVRAS-CHAVE: conhecimento tradicional, etnobotânica, medicina caseira, 


\title{
MEDICINAL PLANTS IN THE URBAN QUINTAIS OF THE ALTO DA CRUZ COMMUNITY IN THE PITIÚ IN BATURITÉ-CE
}

\begin{abstract}
The difficulty in accessing health care by the population that does not have their needs met at health institutions makes them use medicinal plants. Thus, the study aimed to know about the use of medicinal plants in the community of Alto da Cruz in the neighborhood Pitiú in urban area of the municipality of Baturité, Ceará, in the cure of diseases. For that, a quantitative-qualitative structured questionnaire composed of 20 questions related to the use of medicinal plants was applied from may to october 2017 and interviewed 50 people of both sexes aged between 18 and 84 years. The results showed that the majority of respondents were elderly women, who acquired the knowledge of their ancestors. There were 48 medicinal plants distributed in 25 families, Fabaceae and Lamiaceae presented the largest number of species. Chamomile (Matricaria chamomilla) was the most cited species, 16 times (21.3\%), followed by boldo (Peumus boldus) and sweet herb (Pimpinela anisum) with 15 citations (20\%); lemon balm (Melissa officinalis) and mastruz (Dysphania ambrosioides) 14 times (18.7\%). The most used parts of the plant were leaves (49.3\%), bark (13.4\%), seed (10.4\%) and flower (8.9\%), being that root, bast and fruit had equal use citation (6.0\%). The population of Alto da Cruz community uses medicinal plants to maintain health not only by tradition of use that is very strong in the community, but also, due to the financial difficulties to acquire allopathic medicines sold at local pharmacies.
\end{abstract}

KEYWORDS: Etnobotany, traditional knowledge, folk medicine,

\section{INTRODUÇÃO}

É provável que a utilização das plantas como medicamento seja tão antiga como o próprio homem, já que o uso dos recursos vegetais com fins terapêuticos remonta ao início da civilização humana, confundindo-se com a própria origem do homem na busca da cura das doenças pelo uso das plantas medicinais (LUCENA et al., 2013). Por planta medicinal Ângelo e Ribeiro (2014) consideram qualquer extrato natural utilizado para fins terapêuticos. Zago (2018) mostra em seu levantamento sobre a produção do conhecimento científico acerca das plantas medicinais ao longo dos anos, que a diversidade de componentes químicos existentes nas espécies vegetais vem sendo utilizada para tratar várias patologias.

Terapias tradicionais por meio de recursos vegetais estão associadas aos saberes populares, sendo estes construídos ao longo da história e transmitidos ao longo das gerações (SALES et al., 2015). Para Ranieri e Zanirato (2018) esses conhecimentos botânicos são mantidos nas comunidades como patrimônio cultural através das práticas curativas e, pela memória coletiva são salvaguardados os modos de preservar, plantar, colher, reconhecer, usar como alimento ou medicamento.

Esses saberes constituem um patrimônio cultural que deve ser preservado, pois compreendem um vasto acervo de conhecimento sobre plantas utilizadas pela medicina tradicional, suas indicações e formas de preparo (ALMEIDA et al., 2013). Além de, trazer à tona a percepção do passar do tempo, do que existiu, existe e que pode não se manter, pois, sendo dinâmico, está sujeito ao desaparecimento, vulnerável à perda (GONÇALVES, 2015). E estar vulnerável é ser passível de perda, estar exposto a riscos com pouca probabilidade de recuperação (ZANIRATO, 2016).

$O$ uso de plantas medicinais é uma importante ferramenta do resgate de 
saberes tradicionais das populações, além de fortalecer o desenvolvimento e assim favorecer a obtenção de cura. $\mathrm{O}$ uso de plantas medicinais é uma prática de tratamento alternativo ou complementar, largamente difundido, compondo uma prática fundamental para o cuidado integral à saúde (SALES et al., 2015).

Na sabedoria popular o conhecimento é construído coletivamente, com saberes baseados na tradição, e que, apesar de estarem em constante renovação e desenvolvimento, mantêm sua essência e identidade dos povos de origem, geralmente nos quintais de suas casas (SILVA; MILARE, 2018).

Os quintais são sistemas que atuam como uma estratégia de uso mais sustentável dos recursos medicinais por conservarem também as espécies nativas, especialmente os rurais, os urbanos são locais ricos em diversidade vegetal e de conservação da biodiversidade, além da propagação de saberes tradicionais. Entretanto, o habito de cultivar plantas em áreas urbanas está deixando de ser prioridade para as famílias, que vem sendo modificado e adaptado às novas exigências socioeconômicas, em substituição aos tradicionais espaços de terra (PEREIRA et al., 2016). Outro fator relevante é o avanço nas pesquisas e a tendência pelo consumo de produtos naturais e orgânicos, que influenciam na mudança de comportamento da população. Assim, esses ambientes domésticos, principalmente, em zonas periféricas das grandes e médias cidades são usados, sobretudo para a produção de alimentos. O destaque dos quintais também se dá quando o homem aproveita os recursos vegetais como alternativa terapêutica muitas vezes própria de sua cultura (MIRANDA et al., 2016). No que tange à conservação, os quintais urbanos são considerados um verdadeiro banco de recursos genéticos de grande relevância para os seres humanos.

Assim, o estudo objetivou conhecer os usos e quais plantas medicinais são mais frequentes nos quintais urbanos da Comunidade Alto da Cruz em Baturité no Ceará, para combater os problemas de saúde das pessoas.

\section{MATERIAL E MÉTODOS \\ Localização e caracterização da área de estudo}

A pesquisa foi desenvolvida na comunidade do Alto da Cruz localizada em frente à igreja Cristo Rei, no município de Baturité, Ceará, nas seguintes coordenadas geográficas, latitude $4^{\circ} 19^{\prime} 43^{\prime \prime}$ Sul, longitude $38^{\circ} 53^{\prime} 05^{\prime \prime}$ Oeste, em altitude de $175 \mathrm{~m}$. O clima é o tropical quente sub úmido, com temperatura média anual entre 26 a $28^{\circ} \mathrm{C}$ e o período chuvoso de janeiro a maio, com pluviosidade anual de $1.089,7 \mathrm{~mm}$, considerada uma das mais altas do Ceará. O município foi criado em 1763 e em tupi significa Serra Verdadeira, nesta região habitam os descendentes de diversas etnias como os Potyguara, Jenipapo e Kanyndé. Possui uma área $308,780 \mathrm{~km}^{2}$, uma população de 35.351 habitantes com 73,34\% vivendo em área urbana com a economia baseada na exploração do setor terciário pelo comércio e prestação de serviços, com a agricultura voltada para culturas da banana, arroz, milho, feijão, café (IPECE, 2017).

O relevo é de maciços residuais, solos aluviais, planossolo solódico e podzólico vermelho-amarelo. A vegetação é formada pela caatinga arbustiva densa, floresta subcaducifólia tropical pluvial, floresta úmida semiperenofólia, floresta úmida semicaducifólia, floresta caducifólia e mata ciliar do bioma Caatinga. Existe ainda uma APA (Área de Proteção Ambiental). Baturité possui um clima peculiar para esta região do Brasil, onde as máximas atingem $32{ }^{\circ} \mathrm{C}$ nos meses mais quentes e $20^{\circ} \mathrm{C}$ na época mais fria, chegando a ocorrer tempestades com ventos fortes e raios (IPECE, 2017). 
A comunidade Alto da Cruz é composta por famílias de agricultores familiares que migraram do campo para a cidade em busca de emprego, melhor remuneração e educação para os filhos.

\section{Período de estudo}

O trabalho foi realizado de maio a outubro de 2017 com 50 famílias residentes na comunidade Alto da Cruz, cujas pessoas entrevistadas, de ambos os sexos, tinham entre 18 a 84 anos de idade, respondendo ao questionário 42 mulheres e 8 homens.

\section{Caracterização do Estudo}

Inicialmente, os objetivos da pesquisa foram explanados sendo solicitada a colaboração voluntária dos moradores. Uma vez aceita a participação, assinaram o termo de consentimento livre e esclarecido (TCLE) e deu-se início à entrevista. A pesquisa sobre as plantas medicinais foi analisada através das abordagens quantitativa e qualitativa.

\section{Coleta dos dados}

Foi utilizado como recurso metodológico um questionário estruturado quantiqualitativo composto por 20 perguntas que abordavam o conhecimento sobre quais espécies de plantas medicinais são utilizadas pela comunidade, suas indicações terapêuticas, nomes populares, forma e frequência de uso, partes da planta utilizadas, e suas indicações. Também foi perguntado sobre a origem do saber sobre as plantas medicinais. As plantas citadas foram fotografadas, para posterior identificação da espécie.

\section{Análise estatística}

Os dados coletados foram organizados e analisados por meio de métodos da estatística descritiva, com sínteses apresentadas na forma de tabelas pelo Word e Excel. As frequências foram calculadas pela seguinte fórmula:

$$
F p_{i}(\%)=\left(\frac{f_{i}}{n}\right) * 100
$$

onde, $\mathrm{Fp}_{\mathrm{i}}$ : frequência percentual, $\mathrm{f}_{\mathrm{i}}$ : frequência absoluta e $\mathrm{n}$ : número de observações.

\section{RESULTADOS E DISCUSSÃO}

Todas as casas visitadas na comunidade Alto da Cruz possuíam quintais com o cultivo de hortaliças, plantas medicinais, frutíferas, arbóreas e ornamentais. Para Ranieri e Zanirato (2018) os quintais são um patrimônio de conhecimentos na dimensão natural e cultural da integração de saberes sobre plantas, suas formas de manejo e, a conservação efetiva desse patrimônio, depende da parceria com as gerações futuras.

A maior porcentagem de mulheres (84\%) em comparação aos homens (16\%), que responderam ao questionário neste estudo, também foi observado nos trabalhos de Leite e Marinho (2014), Freitas et al. (2015), Ó et al. (2016), que possuem em comum a maior participação da mulher no cultivo de plantas medicinais, pois são elas que cuidam dos seus quintais, independente da região em que vivem. Miranda et al. (2016) ressaltam que o maior número de mulheres pode ser justificado devido os afazeres relacionados ao núcleo familiar estarem, culturalmente, sobre os cuidados da mulher, e nisto se inclui o manejo dos quintais. 
Foram citadas 48 espécies de plantas distribuídas em 25 famílias (Tabela 1). A família Fabaceae e a Lamiaceae apresentaram o maior número de espécies (7) em cada uma, a Astercaceae (6 spp) e, com duas espécies em cada na Apiaceae, Lauraceae, Myrtaceae, Rubiaceae e Rutaceae. Ribeiro et al. (2014) em trabalho no Cariri cearense e Ferreira et al. (2015) em três localidades mato-grossenses também encontraram o maior número de espécies medicinais na família Fabaceae.

As espécies mais citadas foram, camomila (Matricaria chamomilla) 16 vezes (21,3\%), boldo (Peumus boldus) e erva doce (Pimpinela anisum) 15 citações $(20 \%)$; erva cidreira (Melissa officinalis) e mastruz (Dysphania ambrosioides) 14 vezes $(18,7 \%)$; canela (Cinnamomum verum) e hortelã (Mentha sp) 9 vezes (12,\%); alfavaca (Ocimum gratissimum), eucalipto (Eucalyptus globulus) e malvarisco (Plectrantrhus ambroinicus) 6 vezes (8\%); arnica (Solidago polyglossa), capim santo (Cymbopogon citratus), dente de leão (Taraxacum officinale) e mussambê (Cleome spinosa) 5 vezes (6,7\%); aroeira (Myracrodruon urundeuva), corama (Bryophyllum pinnatum), jatobá (Hymenaea courbaril), pepaconha (Cephaelis ipecacuanha) e sena (Senna corymbosa) 4 vezes (5,3\%); agrião (Nasturtium officinalis), alecrim (Rosmarinus officinalis), angico (Anadenanthera colubrina), carqueja (Baccharis genistelloides), cumaru (Dipteryx odorata), guaco (Mikania glomerata), guaraná (Paulinia cupana), jaborandi (Pilocarpus jaborandi), laranjeira (Citrus sinensis), laranja da terra (Citrus aurantium), macela (Achyrocline satureioides), malva (Malva silvestris ), oliveira ou azeitona-preta (Syzygium cumini (L.) Skeels) e romã (Punica granatum) 3 vezes (4\%); alcaçuz (Glycyrrhiza glabra), alfazema (Lavanda ssp), ameixa da caatinga (Ximenia americana), arruda (Ruta graveolens), coentro (Coriandum sativum), cravo da índia (Syzygium aromaticum), louro (Laurus nobilis), pata de vaca (Bauhinia forficata) e unha de gato (Uncaria tomentosa) 2 vezes $(2,7 \%)$. Menos citadas foram o alho, babosa, confrei, pimenta, tamarindo e valeriana citadas somente $1 \mathrm{vez}(1,3 \%)$ pelos entrevistados.

TABELA 1 - Plantas medicinais citadas na Comunidade Alto da Cruz, Baturité, CE.

\begin{tabular}{cccc}
\hline Família & Nome Científico & Nome Popular & Número de Citações \\
\hline Amaryllidaceae & Allium sativum & Alho & 01 \\
Anacardiaceae & Myracrodruon urundeuva & Aroeira & 04 \\
Asphodelaceae & Aloe vera & Babosa & 01 \\
Apiaceae & Pimpinella anisum & Erva doce & 15 \\
& Coriandum sativum & Coentro & 02 \\
Asteraceae & Matricaria chamomilla & Camomila & 16 \\
& Achyrocline satureioides & Macela & 03 \\
& Baccharis genistelloides & Carqueja & 03 \\
& Mikania glomerata & Guaco & 03 \\
& Solidago polyglossa & Arnica & 05 \\
Boraginaceae & Taraxacum officinale & Dente de leão & 05 \\
Brassicaceae & Symphytum officinale & Confrei & 01 \\
Capparaceae & Nasturtium officinalis & Agrião & 03 \\
Caprifoliaceae & Cleome spinosa & Mussambê & 05 \\
Chenopodiaceae & Valeriana officinalis & Valeriana & 01 \\
Crassulaceae & Dyphania ambrosioides & Mastruz & 14 \\
Fabaceae & Bryophyllum pinnatum & Corama & 04 \\
& Tamarindus indica & Tamarindo & 01 \\
& Glycyrrhiza glabra & Alcaçuz & 02 \\
& Bauhinia forficata & Pata de vaca & 02 \\
& Hymenaea courbaril & Jatobá & 04 \\
& Dipteryx odorata & Cumaru & 03 \\
& Anadenanthera colubrina & Angico & 03
\end{tabular}




$\begin{array}{cccc} & \text { Senna corymbosa } & \text { Sena } & 04 \\ \text { Lamiaceae } & \text { Mentha sp } & \text { Hortelã } & 09 \\ & \text { Rosmarinus officinalis } & \text { Alecrim } & 03 \\ & \text { Melissa officinales } & \text { Erva cidreira } & 14 \\ & \text { Peumus boldus } & \text { Boldo } & 15 \\ & \text { Plectrantrhus ambroinicus } & \text { Malvarisco } & 06 \\ & \text { Ocimum gratissimum } & \text { Alfavaca } & 06 \\ \text { Lauraceae } & \text { Lavanda ssp } & \text { Alfazema } & 02 \\ & \text { Laurus nobilis } & \text { Louro } & 02 \\ \text { Malvaceae } & \text { Cinnamomum verum } & \text { Canela } & 09 \\ \text { Myrtaceae } & \text { Malva silvestris } & \text { Malva } & 03 \\ & \text { Syzygium aromaticum } & \text { Cravo da índia } & 02 \\ \text { Olacaceae } & \text { Eucalyptus globulus } & \text { Eucalipto } & 06 \\ \text { Myrtaceae } & \text { Ximenia americana L } & \text { Ameixa da caatinga } & 02 \\ & \text { Syzygium cumini (L.) } & \text { Oliveira ou Azeitona- } & 03 \\ \text { Poaceae } & \text { Skeels } & \text { preta } & \\ \text { Punicaceae } & \text { Cymbopogon citratus } & \text { Capim santo } & 05 \\ \text { Rubiaceae } & \text { Punica granatum L } & \text { Romã } & 03 \\ & \text { Uncaria tomentosa } & \text { Unha de gato } & 02 \\ \text { Rutaceae } & \text { Cephaelis ipecacuanha } & \text { Pepaconha } & 04 \\ & \text { Citrus sinensis } & \text { Laranjeira } & 03 \\ \text { Rutáceas } & \text { Citrus aurantium } & \text { Laranja da terra } & 03 \\ & \text { Ruta graveolens } & \text { Arruda } & 02 \\ \text { Sapindaceae } & \text { Pilocarpus jaborandi } & \text { Jaborandi } & 03 \\ \text { Solanaceae } & \text { Paulinia cupana } & \text { Guaraná } & 03 \\ & \text { Capsicum spp } & \text { Pimenta } & 01\end{array}$

Fernandes e Krupek (2014) tiveram a camomila como a espécie mais citada, seguida da hortelã e do boldo em entrevista com idosos na região sul do Brasil. Gama e Silva (2006), que também entrevistaram idosos, na cidade de São Paulo, tiveram como mais citadas a camomila a erva-cidreira e a erva-doce. Pereira et al. (2016) encontraram a hortelã e o boldo como os mais citados.

Percebe-se que independente da região do país certas plantas medicinais estão entre as mais usadas pelas populações para o tratamento de problemas de saúde, assim como, o uso de plantas medicinais é uma ferramenta terapêutica e cultural importante, largamente utilizado pelas populações das periferias para a obtenção da cura de agravos (ALMEIDA, 2015). Essas curas populares são um saber herdado oralmente dos mais velhos, por alguns membros de certas famílias ou, podem ser adquiridos na vivência social, como prática no cuidado da saúde, exercido desde o início da colonização, fazendo parte da história e da realidade local (LIMA et al., 2016).

$\mathrm{Na}$ comunidade Alto da Cruz, o baixo número de espécies nativas utilizado, provavelmente, esteja relacionado ao fácil cultivo nos quintais das espécies exóticas específicas para fins terapêuticos, bem como para ampliar as possibilidades de cura das afecções mais comuns das famílias. Outro fato pelo menor número de espécies nativas de plantas medicinais ter sido encontrado nos quintais urbanos da comunidade se deva ao tamanho destes ser inferior aos de comunidades rurais, como também a necessidade deste espaço ao redor das casas ser para o cultivo de espécies vegetais e criação de animais que supram as necessidades nutricionais das famílias.

Dentre as diferentes partes da planta utilizadas para o uso do princípio ativo das plantas medicinais, as mais citadas foram as folhas $(49,3 \%)$, seguidas por cascas $(13,4 \%)$, semente $(10,4 \%)$ e flor $(8,9 \%)$, sendo que a raiz, a entrecasca e o 
fruto tiveram igual citação de uso $(6,0 \%)$. Ribeiro et al. (2014) encontraram sequência semelhante de partes das plantas utilizadas, a folha recebeu maior número de citações de uso, seguida da casca, semente, raiz, fruto e entrecasca. A folha é a parte do vegetal significativamente mais utilizada na medicina caseira de várias localidades, tanto rurais quanto urbanas para o tratamento de doenças, como apresentado nos trabalhos de Ribeiro et al. (2014) em comunidade rural no sul do estado do Ceará e Teixeira et al. (2014) em quintais urbanos de Sobral no norte do Ceará e os achados de Leite et al. (2015) na zona rural de São José das Espinharas na região central do estado da Paraíba e de Cruz et al. (2017) em quintais urbanos no Pará. Santos et al. (2018) salientam que a predominância das folhas serem usadas nos remédios caseiros deve ser atribuída à maior facilidade de coleta e em algumas espécies a disponibilidade durante todo o ano,

O uso da casca é citado em outros estudos etnobotânicos do nordeste brasileiro, como sendo a segunda parte vegetal mais utilizada para a obtenção dos medicamentos caseiros (LEITE et al., 2015), assim como o encontrado neste estudo onde a casca foi a segunda mais citada $(13,4 \%)$ após as folhas $(49,3 \%)$ na comunidade Alto da Cruz em Baturité no estado do Ceará.

Já Silva et al. (2015) observaram que os moradores da comunidade do Sítio Nazaré, no município de Milagres-CE, utilizam predominantemente as raízes para o preparo de seus remédios caseiros. As plantas medicinais não possuem uma distribuição homogênea de seus compostos químicos nas diferentes partes como raízes, rizomas, talos, caules, sementes, folhas e/ou flores, podendo variar muito 0 teor do princípio ativo (BADKE et al., 2016).

O estudo mostra que o chá, tanto por decocção ou por infusão foi o modo mais utilizado para a obtenção dos remédios caseiros, verificou-se que a forma de chá é a mais utilizada $(86 \%)$, seguida da forma de lambedor (14\%). Leite et al. (2015) também observaram que a forma de chá foi a mais utilizada (50\%), seguida da forma de lambedor (44\%). O chá também se destacou como o modo de consumo mais recorrente nos trabalhos de Cruz et al. (2017) e Santos et al. (2018). Os chás devem ser preparados, de preferência, em doses individuais para serem usados logo em seguida. Quando, porém, as doses são muito frequentes, podem ser preparados em quantidade maior, para consumo no mesmo dia. Os chás podem ser preparados de duas formas: por infusão, onde a água é aquecida até o ponto de ebulição e vertida sobre a planta com a mistura ficando em repouso por alguns minutos, de preferência tampada. Esta técnica é geralmente aplicada para preparação de chás de folhas, flores e frutos moídos e preserva o óleo essencial. Já na decocção, as partes da planta são fervidas junto com a água por alguns minutos, aplicada geralmente para o preparo de chás das cascas, entrecascas, sementes e raízes, que por serem mais duros precisam de um método mais rigoroso para a extração dos compostos benéficos presentes na planta.

Observou-se que uma mesma planta é usada para debelar diferentes patologias. Neste estudo, as espécies usadas com menor frequência $(1,3 \%)$ foram alho, babosa, confrei, pimenta, tamarindo e valeriana possuem a característica de ser utilizadas na comunidade Alto da Cruz em situações de infecções. Em trabalhos realizados no Nordeste brasileiro Leite et al. (2015), Silva et al. (2015) e Silva et al. (2018) também encontraram essa diversidade de indicações de uso medicinal para a mesma planta, tanto para o uso frequente em problemas respiratórios (gripe, resfriado, tosse, dor de garganta, bronquite e asma) como em problemas digestivos (má digestão, diarreia, gastrite, úlceras e problemas hepáticos) e nervosos (dor de cabeça e nervosismo). 
QUADRO 1 - Plantas medicinais citadas na Comunidade Alto da Cruz, do município de Baturité, Ceará.

\begin{tabular}{|c|c|c|c|}
\hline $\begin{array}{l}\text { Nome Popular } \\
\text { (no vezes citada) }\end{array}$ & Parte da planta & Forma de uso & Indicação popular \\
\hline Camomila (16) & Flor/semente & Decocção & $\begin{array}{l}\text { Calmante, dor de estômago } \\
\text { Dor de cabeça }\end{array}$ \\
\hline Boldo (15) & Folha & Decocção & Problemas hepáticos, gripe \\
\hline Erva doce (15) & Semente & Decocção & Problemas gastrointestinais \\
\hline Erva cidreira (14) & Folha & $\begin{array}{l}\text { Decocção } \\
\text { Infusão }\end{array}$ & $\begin{array}{l}\text { Calmante, gripe e resfriado } \\
\text { Pressão alta, diarreia }\end{array}$ \\
\hline Mastruz (14) & $\begin{array}{l}\text { Folha } \\
\text { Semente }\end{array}$ & $\begin{array}{l}\text { Decocção } \\
\text { Sumo e suco }\end{array}$ & $\begin{array}{l}\text { Fraturas, cicatrizante } \\
\text { Reumatismo, úlceras }\end{array}$ \\
\hline Canela (9) & Folha/casca & Decocção & Dor muscular, diabete \\
\hline Hortelã (9) & Folha & $\begin{array}{l}\text { Decocção } \\
\text { Lambedor }\end{array}$ & $\begin{array}{l}\text { Problemas gastrointestinais } \\
\text { Problemas respiratórios }\end{array}$ \\
\hline Alfavaca (6) & Folha & Decoccão & Gripe, coriza, fígado \\
\hline Eucalipto (6) & Folha & $\begin{array}{l}\text { Decocção } \\
\text { Infusão }\end{array}$ & $\begin{array}{l}\text { Resfriado, asma, gripe } \\
\text { Congestão nasal, febre }\end{array}$ \\
\hline Malvarisco (6) & Folha & Decocção & Anti-inflamatório \\
\hline Arnica (5) & Flores & Infusão & Cicatrizante, anemia, fígado \\
\hline Capim santo (5) & Folha & Decocção & Calmante, gripe \\
\hline Dente de leão (5) & Folha/raiz & Infusão & Problemas renais e gota \\
\hline Mussambê (5) & $\begin{array}{l}\text { Folha/ } \\
\text { Flor/raiz }\end{array}$ & $\begin{array}{l}\text { Decocção } \\
\text { Infusão }\end{array}$ & $\begin{array}{l}\text { Anti-inflamatório, Bronquite } \\
\text { Gripe }\end{array}$ \\
\hline Aroeira (4) & $\begin{array}{l}\text { Folha/casca } \\
\text { Entrecasca }\end{array}$ & $\begin{array}{l}\text { Decocção } \\
\text { Infusão }\end{array}$ & $\begin{array}{l}\text { Anti-inflamatório, tosse } \\
\text { Queimadura, cicatrizante }\end{array}$ \\
\hline Corama (4) & Folha & Decocção & Anti-inflamatório \\
\hline Jatobá (4) & Casca/entrecasca & Lambedor & Cicatrizante, anemia, tosse \\
\hline Pepaconha (4) & Raiz & Decocção & Cicatrizante, vermes, gripe \\
\hline Sena (4) & Folha & Decocção & Prisão de ventre \\
\hline Agrião (3) & Folha/semente & Decocção & Diurético, cicatrizante \\
\hline Alecrim (3) & Folha & Decoccão & Dores/anti-inflamatório, gripe \\
\hline Angico (3) & $\begin{array}{l}\text { Casca } \\
\text { Entrecasca }\end{array}$ & $\begin{array}{l}\text { Decocção } \\
\text { Lambedor }\end{array}$ & $\begin{array}{l}\text { Problemas respiratórios } \\
\text { Anti-inflamatório, febre }\end{array}$ \\
\hline Carqueja (3) & Folha & Decocção & $\begin{array}{l}\text { Analgésico, anti-inflamatório } \\
\text { Problema hepático, inchaço }\end{array}$ \\
\hline Cumaru (3) & Casca & Decocção & $\begin{array}{l}\text { Problemas respiratórios Gripe, } \\
\text { sinusite }\end{array}$ \\
\hline Guaco (3) & Folha & $\begin{array}{l}\text { Decocção } \\
\text { Lambedor }\end{array}$ & $\begin{array}{l}\text { Tosse e gripe } \\
\text { Verminose, febre }\end{array}$ \\
\hline Guaraná (3) & Fruto & Pó com suco & Cardiotônico, estimulante \\
\hline Jaborandi (3) & Folha & Infusão & Reumatismo \\
\hline Laranja (3) & $\begin{array}{l}\text { Folha } \\
\text { Casca do fruto }\end{array}$ & $\begin{array}{l}\text { Decocção } \\
\text { Lambedor }\end{array}$ & $\begin{array}{l}\text { Digestão, gripe, febre } \\
\text { Calmante }\end{array}$ \\
\hline Laranja da terra (3) & $\begin{array}{l}\text { Folha/casca do } \\
\text { fruto }\end{array}$ & Decocção & Inibir o apetite \\
\hline Macela (3) & $\begin{array}{l}\text { Flor } \\
\text { Semente }\end{array}$ & $\begin{array}{l}\text { Decocção } \\
\text { Infusão }\end{array}$ & $\begin{array}{l}\text { Má digestão, reumatismo } \\
\text { Problemas hepáticos }\end{array}$ \\
\hline Malva (3) & Folha & Decocção & $\begin{array}{l}\text { Dor de garganta, tosse seca } \\
\text { Cicatrizante }\end{array}$ \\
\hline $\begin{array}{l}\text { Oliveira ou } \\
\text { Azeitona-preta (3) }\end{array}$ & Folha & Decocção & Asma, constipação \\
\hline Romã (3) & $\begin{array}{l}\text { Casca } \\
\text { Semente/fruto }\end{array}$ & $\begin{array}{l}\text { Decocção } \\
\text { Lambedor }\end{array}$ & $\begin{array}{l}\text { Inflamação da garganta } \\
\text { Tosse, gastrite, sinusite }\end{array}$ \\
\hline Alcaçuz (2) & Raiz & Decocção & Laxante e dor de garganta \\
\hline Alfazema (2) & Folha/Flor & Infusão & Anemia, depressão, diarreia \\
\hline $\begin{array}{l}\text { Ameixa da caatinga } \\
\text { (2) }\end{array}$ & $\begin{array}{l}\text { Folha } \\
\text { Casca/entrecasca }\end{array}$ & Decocção Infusão & $\begin{array}{l}\text { Cicatrizante, relaxante } \\
\text { Anti-inflamatório }\end{array}$ \\
\hline
\end{tabular}




\begin{tabular}{|l|l|l|l|}
\hline Arruda (2) & Folha & $\begin{array}{l}\text { Decocção } \\
\text { Infusão, sumo }\end{array}$ & $\begin{array}{l}\text { Vermes, epilepsia } \\
\text { Cólicas }\end{array}$ \\
\hline Coentro (2) & Semente & Decocção & Problema hepático, diarreia \\
\hline Cravo da índia (2) & Botões florais & Decocção & Cólica menstrual \\
\hline Louro (2) & Folha & Decção & Hemorroida, gripe, diarreia \\
\hline Pata de vaca (2) & Folha & Infusão & Diabete \\
\hline Unha de gato (2) & Broto da folha & Decocção & Artrite e amigdalite \\
\hline Alho (1) & Fruto & $\begin{array}{l}\text { Decocção } \\
\text { Lambedor }\end{array}$ & $\begin{array}{l}\text { Vermes, gripe, cólicas } \\
\text { Anti-inflamatório, fraqueza }\end{array}$ \\
\hline Babosa (1) & Folha & $\begin{array}{l}\text { Lambedor } \\
\text { Sumo }\end{array}$ & $\begin{array}{l}\text { Cicatrizante, cabelo } \\
\text { Anti-inflamatório, gripe }\end{array}$ \\
\hline Confrei (1) & Folha & Decocção & Inflamação e dor \\
\hline Pimenta (1) & Folha & Decocção & Reumatismo, febre \\
\hline Tamarindo (1) & Fruto & Suco & Inflamações e febres \\
\hline Valeriana (1) & Folha & Decocção & Nervosismo \\
\hline
\end{tabular}

A população da comunidade Alto da Cruz utiliza plantas medicinais para manter a saúde não só por tradição de uso que é bem forte na comunidade, mas também, em função das dificuldades financeiras para adquirir medicamentos alopáticos vendidos nas farmácias locais.

\section{CONCLUSÃO}

O conhecimento tradicional dos comunitários do bairro Pitiú na comunidade Alto da Cruz em Baturité dinamiza a produção dos remédios caseiros com camomila, boldo e erva doce, na cura das enfermidades mais frequentes e, o entendimento sobre a indicação terapêutica e a utilização das plantas teve origem no saber popular repassado pelos pais, familiares ou amigos.

\section{REFERÊNCIAS}

ALMEIDA, L.S.; GAMA, J.R.V.; OLIVEIRA, F.A.; FERREIRA, M.S.G.; MENEZES, A.J.E.A.; GONÇALVES, D.C.M. Uso de espécies da flora na comunidade rural Santo Antônio, BR-163 Amazônia Brasileira. Floresta e Ambiente, v. 20, n. 4, p. 435-446, 2013. Disponível em: http://www.scielo.br/pdf/floram/v20n4/a02v20n4.pdf DOI: 10.4322/floram.2013.044

ALMEIDA, D.H. O reconhecimento dos curadores populares e a construção de uma identidade médica no Brasil oitocentista. Ciencias Sociales y Educación, v. 4, n. 8, p. 141-154, 2015. ISSN 2256-5000. Disponível em: https://revistas.udem.edu.co/index.php/Ciencias_Sociales/article/download/1748/167 8 Acesso em: 02/02/2019.

ÂNGELO, T.; RIBEIRO, C.C. Utilização de plantas medicinais e medicamentos fitoterápicos por idosos. Revista Eletrônica da Fainor, v. 7, n. 1, p. 18-31, 2014. Disponível em: http://srv02.fainor.com.br/revista/index.php/memorias/article/viewFile/246/188

BADKE, M.R.; SOMAVILLA, C.A.; HEISLER, E.V.; ANDRADE, A.; BUDÓ, M.L.D; GARLET, T.M.B. Saber popular: uso de plantas medicinais como forma terapêutica no cuidado à saúde. Revista de Enfermagem da UFSM, v. 6, n. 2, p. 225-234, 2016. Disponível em: https://periodicos.ufsm.br/reufsm/article/view/17945/pdf DOl: $10.5902 / 2179769217945$ 
CRUZ, V.M.S.; GONÇALVES, AL.; CAMPOS, J.R.P.; REIS, A.R.S. Aspectos socioeconômicos e o cultivo de plantas medicinais em quintais agroflorestais urbanos (qaf) no município de Breu Branco, Pará, Brasil. Enciclopédia Biosfera, Centro Científico Conhecer, v. 14 n. 25; p. 158-170, 2017. Disponível em: http://www.conhecer.org.br/enciclop/2017a/agrar/aspectos\%20socioeconomicos.pdf DOI: 10.18677/EnciBio_2017A15]

FERNANDES, N.K.; KRUPEK, R.A. O uso de plantas medicinais por grupos da terceira idade no município de União da Vitória (PR). Arquivos do MUDI, v. 18, n. 3, p. 49-64, 2014. Disponível em: <www.periodicos.uem.br/ojs/index.php/ArqMudi/article/download/26905/pdf_81>. Acesso em: 10/01/2019

FERREIRA, A.L.S.; BATISTA, C.A.S.; PASA, M.C. Levantamento etnobotânico nas diferentes realidades de ensino. Biodiversidade, v. 14, n. 3, p. 60-73, 2015. Disponível em:http://periodicoscientificos.ufmt.br/ojs/index.php/biodiversidade/article/view/3189/ 2246 Acesso em: 11/01/2019

FREITAS, A.V.L.; COELHO, M.F.B.; PEREIRA, Y.B.; FREITAS NETO, E.C.; AZEVEDO, R.A.B. Diversidade e usos de plantas medicinais nos quintais da comunidade de São João da Várzea em Mossoró, RN. Revista Brasileira de Plantas Medicinais, v. 17, n. 4, supl. II, p. 845-856, 2015. Disponível em: http://www.scielo.br/pdf/rbpm/v17n4s2/1516-0572-rbpm-17-4-s2-0845.pdf DOI 10.1590/1983-084X/14_080

GAMA, X.; SILVA, M.A.P. A utilização da fitoterapia por idosos de um centro de saúde em área central da cidade de São Paulo. Saúde Coletiva, v. 11, n. 3, p. 7984, 2006. ISSN: 1806-3365. Disponível em: https://www.redalyc.org/articulo.oa?id=84212137004 Acesso em: 12/01/2019

GONÇALVES, J. R. S. O mal-estar no patrimônio: identidade, tempo e destruição. Estudos Históricos, v. 28, n. 55, p. 211-228, 2015. Disponível em: http://www.scielo.br/pdf/eh/v28n55/0103-2186-eh-28-55-0211.pdf DOI: $10.1590 /$ S0103-21862015000100012

IPECE - Instituto de Pesquisa e Estratégia econômica do Ceará - Perfil municipal de Redenção, 2017. Disponível em: http://www2.ipece.ce.gov.br/estatistica/perfil_regional/2017/PR_Macico_de_Baturite_ 2017.pdf Acesso em: 12/01/2019

LEITE, I.A.; MARINHO, M.G.V. Levantamento etnobotânico de plantas medicinais em comunidade indígena no município de Baía da Traição-PB. Biodiversidade, v. 13, n. 1, p. 82-105, 2014. Disponível em: http://periodicoscientificos.ufmt.br/ojs/index.php/biodiversidade/article/view/1542/121 2 Acesso em: 09/01/2019

LEITE, I.A.; MORAIS, A.M.; Ó, K.D.S.; CARNEIRO, R.G.; LEITE, C.A. A etnobotânica de plantas medicinais no município de São José de Espinharas, Paraíba, Brasil. Biodiversidade, v. 14, n. 1, p. 22-30, 2015. Disponível em: http://periodicoscientificos.ufmt.br/ojs/index.php/biodiversidade/article/view/2249/161 8 Acesso em: 11/01/2019. 
LIMA, C.A.B.; LIMA, A.R.A.; MENDONÇA, C.V.; LOPES, C.V.; HECK, R.M. O uso das plantas medicinais e o papel da fé no cuidado familiar. Revista Gaúcha de Enfermagem, v. 37, p. 1-10, 2016. Disponível em: https://seer.ufrgs.br/RevistaGauchadeEnfermagem/article/view/68285/41066 DOI: 10.1590/1983-1447.2016.esp.68285.

LUCENA, D. S; FONSÊCA, C. M. B.; MARINHO, M. G. V.; SOUZA, P. F. Estudo comparativo sobre o uso de plantas medicinais em duas cidades paraibanas pertencentes às mesorregiões do sertão e do Curimataú Ocidental. Revista da Biologia e Farmácia, v. 9, n. 4, p. 1-14, 2013. ISSN 1983-4209. Disponível em: https://docplayer.com.br/13835087-Estudo-comparativo-sobre-o-uso-de-plantasmedicinais-em-duas-cidades-paraibanas-pertencentes-as-mesorregioes-do-sertao-edo-curimatau-ocidental.html Acesso em: 11/01/2019.

MIRANDA; T.G.; OLIVEIRA JÚNIOR, J.F.; MARTINS JUNIOR, A.S.; TAVARES MARTINS, A.C.C. O uso de plantas em quintais urbanos no bairro da Francilândia no município de Abaetetuba, Pará, Brasil. Scientia Plena, v. 12, n. 6, p. 1-18, 2016. Disponível em: https://www.scientiaplena.org.br/sp/article/view/3058/1449 DOI: 10.14808/sci.plena.2016.069909

Ó, K.D.S.; SILVA, G.H.; LEITE, I.A. Estudo etnobotânico de plantas medicinais em duas comunidades no estado da Paraíba, Brasil. Biodiversidade, v. 15, n. 2, p. 5361 , 2016.

Disponível em:http://periodicoscientificos.ufmt.br/ojs/index.php/biodiversidade/article/view/3960/ 2755 Acesso em: 13/01/2019.

PEREIRA, N.V.; MAGALHÃES, T.R.; MACEDO, T.; PASA, M.C. Recursos vegetais e o saber local: uso de plantas medicinais no horto florestal Toti Garcia. Cuiabá MT. Biodiversidade, v. 15, n. 2, p. 124-135, 2016. Disponível em: http://periodicoscientificos.ufmt.br/ojs/index.php/biodiversidade/article/view/3965/276 0 Acesso em: 11/01/2019.

RANIERI, G.R.; ZANIRATO, S.H. Conhecimento etnobotânico como patrimônio: os quintais urbanos nas pequenas cidades do vale histórico paulista. Desenvolvimento e Meio Ambiente, v. 49, p. 183-199, 2018. Disponível em: https://revistas.ufpr.br/made/article/view/58220 DOI: 10.5380/dma.v49i0.58220.

RIBEIRO, D.A.; MACÊDO, D.G.; OLIVEIRA, L.G.S.; SARAIVA, M.E.; OLIVEIRA, S.F. et al. Potencial terapêutico e uso de plantas medicinais em uma área de Caatinga no estado do Ceará, nordeste do Brasil. Revista Brasileira de Plantas Medicinais, v. 16, n. 4, p. 912-930, 2014. Disponível em: http://www.scielo.br/pdf/rbpm/v16n4/a18v16n4.pdf DOI: 10.1590/1983-084X/13_059 Acesso em: 13/01/2019.

SALES, M.D.C.; SARTOR, E.B.; GENTILLI, R.M.L. Etnobotânica e Etnofarmacologia: medicina tradicional e bioprospecção de fitoterápicos. Revista Salus Journal Health Sciences, v. 1, n. 1, p. 17-26, 2015. Disponível em: $<$ http://www.salusjournal.org/wp-content/plugins/download attachments/includes/download.php?id=691 >. DOI: https://dx.doi.org/10.5935/24477826.20150003

SANTOS, L.S.N.; SALLES, M.G.F.; PINTO, C.M.; PINTO, O.R.O.; RODRIGUES, 
I.C.S. O saber etnobotânico sobre plantas medicinais na Comunidade da Brenha, Redenção, CE. Agrarian Academy, Centro Científico Conhecer, v. 5, n. 9; p. 409421, $2018 . \quad$ Disponível em: http://www.conhecer.org.br/Agrarian\%20Academy/2018a/o\%20saber.pdf DOI: 10.18677/Agrarian_Academy_2018a40

SILVA, C.G.; MARINHO, M.G.V.; LUCENA, M.F.A.; COSTA, J.G.M. Levantamento etnobotânico de plantas medicinais em área de Caatinga na comunidade do Sítio Nazaré, município de Milagres, Ceará, Brasil. Revista Brasileira de Plantas Medicinais, v. 17, n. 1, p. 133-142, 2015. Disponível em: http://www.scielo.br/pdf/rbpm/v17n1/1983-084X-rbpm-17-01-00133.pdf DOI: 10.1590/1983-084X/12_055.

SILVA, L.A.R.; MILARÉ, T. Os significados e a natureza dos saberes populares: reflexões e possibilidades no ensino de ciências. Ensaios Pedagógicos, v. 2, n. 3, p. 95-100, 2018, ISSN: 2527-158X Disponívelol em: http://www.ensaiospedagogicos.ufscar.br/index.php/ENP/article/view/99/140 Acesso em: 11/01/2019.

SILVA, P.H.; OLIVEIRA, I.R.; ABREU, M.C. Entre símbolos, mistérios e a cura: plantas místicas dos quintais de uma comunidade rural piauiense. Gaia Scientia, v. 12, n. 1, p. 1-16, 2018. ISSN 1981-1268. Disponível em: http://www.periodicos.ufpb.br/index.php/gaia/article/download/33196/19764 Acesso em: 03/02/2019.

TEIXEIRA, A.H.; BEZERRA, M.M.; CHAVES, H.V.; VAL, D.R.; PEREIRA FILHO, S.M.P; SILVA, A.A.R. Conhecimento popular sobre o uso de plantas medicinais no município de Sobral-Ceará, Brasil. S A N A R E, v. 13, n. 1, p. 23-28, 2014. Disponível em: https://sanare.emnuvens.com.br/sanare/article/viewFile/429/284 Acesso: 11/01/2019.

ZAGO, L.M.S. Vinte e dois anos de pesquisa sobre plantas medicinais: uma análise cienciométrica.Tecnia, v. 3, n. 1, p. 157-173, 2018. ISSN: 2526-2130. Disponível em: http://revistas.ifg.edu.br/tecnia/article/view/157 Acesso em: 11/03/2019

ZANIRATO, S. H. Patrimônio cultural e sustentabilidade: uma associação plausível? Revista Confluências Culturais, v. 5, n. 2, p. 200-211, 2016. Disponível em: http://periodicos.univille.br/index.php/RCCult/article/view/321/309

DOI: 10.21726/rccult.v5i2.321 


\section{APÊNDICE}

Quadro 2. Questionário semiestruturado sobre as plantas medicinais.

\begin{tabular}{|c|c|c|c|c|c|}
\hline $\begin{array}{l}\text { 1) Já utilizou ou utiliza } \\
\text { Plantas Medicinais }\end{array}$ & $\begin{array}{l}(\mathrm{)}) \\
\text { Sim }\end{array}$ & Não & & & \\
\hline 2) Com qual frequência & $\begin{array}{c}\text { ( ) } \\
\text { Casualmente }\end{array}$ & $\begin{array}{c}(\text { ) } \\
\text { Frequentemente }\end{array}$ & & & \\
\hline $\begin{array}{l}\text { 3) Finalidade de usar } \\
\text { plantas medicinais }\end{array}$ & $\begin{array}{c}\text { ( ) } \\
\text { Hábito }\end{array}$ & $\begin{array}{c}(\text { ) } \\
\text { Enfermidade }\end{array}$ & & & \\
\hline $\begin{array}{l}\text { 4) Que faixa etária usa } \\
\text { mais as plantas } \\
\text { medicinais }\end{array}$ & $\begin{array}{c}\text { ( ) } \\
\text { Crianças }\end{array}$ & $\begin{array}{c}\text { ( ) } \\
\text { Jovens }\end{array}$ & $\begin{array}{c}(\text { ) } \\
\text { Adultos }\end{array}$ & $\begin{array}{c}\text { ( ) } \\
\text { Idosos }\end{array}$ & \\
\hline $\begin{array}{l}\text { 5) Que espécies } \\
\text { costuma utilizar }\end{array}$ & & & & & \\
\hline $\begin{array}{l}\text { 6) Qual o nome } \\
\text { popular da planta }\end{array}$ & & & & & \\
\hline $\begin{array}{l}\text { 7) A planta é cultivada, } \\
\text { nativa ou espontânea }\end{array}$ & & & & & \\
\hline $\begin{array}{l}\text { 8) Para qual doença a } \\
\text { planta é utilizada }\end{array}$ & & & & & \\
\hline $\begin{array}{l}\text { 9) Consegue a cura } \\
\text { utilizando a planta } \\
\text { medicinal }\end{array}$ & & & & & \\
\hline $\begin{array}{l}\text { 10) Qual é o tempo de } \\
\text { tratamento }\end{array}$ & & & & & \\
\hline $\begin{array}{l}\text { 11) Quais plantas } \\
\text { cultivam no quintal }\end{array}$ & & & & & \\
\hline 12) Qual parte da & $\begin{array}{c}\text { ( ) } \\
\text { Caule }\end{array}$ & $\begin{array}{l}\text { ( ) } \\
\text { Raiz }\end{array}$ & $\begin{array}{c}(\text { ) } \\
\text { Casca do } \\
\text { caule }\end{array}$ & $\begin{array}{l}(\stackrel{)}{)} \\
\text { Flor }\end{array}$ & $\begin{array}{c}(\text { ) } \\
\text { Semente }\end{array}$ \\
\hline planta é utilizada & $\begin{array}{c}\text { ( ) } \\
\text { Planta inteira }\end{array}$ & $\begin{array}{c}\text { ( ) } \\
\text { Ramos }\end{array}$ & $\begin{array}{c}(\text { ) } \\
\text { Broto das } \\
\text { folhas }\end{array}$ & $\begin{array}{c}(\text { ) } \\
\text { Tubérculo }\end{array}$ & $\begin{array}{c}(.) \\
\text { Casca do } \\
\text { fruto }\end{array}$ \\
\hline $\begin{array}{l}\text { 13) Estado de uso da } \\
\text { planta }\end{array}$ & $\begin{array}{l}(\text { ) } \\
\text { Seca }\end{array}$ & $\begin{array}{l}() \\
\text { Verde }\end{array}$ & & & \\
\hline 14) Forma de uso da & $\begin{array}{l}\text { ( ) } \\
\text { Chá }\end{array}$ & $\begin{array}{c}(\text { ) } \\
\text { Gargarejo }\end{array}$ & $\begin{array}{c}(\text { ) } \\
\text { Banho }\end{array}$ & $\begin{array}{c}(\text { ) } \\
\text { Decocção }\end{array}$ & $\begin{array}{c}\text { ( ) } \\
\text { Infusão }\end{array}$ \\
\hline planta & $\begin{array}{c}\text { ( ) } \\
\text { Maceração }\end{array}$ & $\begin{array}{c}\text { ( ) } \\
\text { Garrafadas }\end{array}$ & $\begin{array}{c}(\text { ) } \\
\text { Compressas }\end{array}$ & $\begin{array}{c}\text { ( ) } \\
\text { Cataplasmas }\end{array}$ & $\begin{array}{c}\text { ( ) } \\
\text { Pomadas }\end{array}$ \\
\hline $\begin{array}{l}\text { 15) Quem ensinou } \\
\text { sobre o uso de plantas }\end{array}$ & $\begin{array}{l}\text { ( ) } \\
\text { Bisavós }\end{array}$ & $\begin{array}{c}\text { ( ) } \\
\text { Avós }\end{array}$ & $\begin{array}{l}() \\
\text { Tios } \\
\end{array}$ & $\begin{array}{c}(\text { ) } \\
\text { Outros }\end{array}$ & \\
\hline $\begin{array}{l}\text { 16) Há contra } \\
\text { indicação da planta }\end{array}$ & Sim & Não & & & \\
\hline $\begin{array}{l}\text { 17) Forma de vida da } \\
\text { planta }\end{array}$ & $\begin{array}{c}\text { ( ) } \\
\text { Arbusto }\end{array}$ & Árvore & $\begin{array}{c}\text { ( ) } \\
\text { Subarbusto } \\
\text { herbáceo }\end{array}$ & 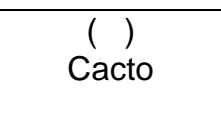 & \\
\hline $\begin{array}{l}\text { 18) Usa plantas como } \\
\text { remédios por quê }\end{array}$ & $\begin{array}{c}(\mathrm{)}) \\
\text { Mais barato }\end{array}$ & $\begin{array}{l}\text { ( ) } \\
\text { Não faz mal à } \\
\text { saúde }\end{array}$ & $\begin{array}{c}(\stackrel{)}{)}) \\
\text { Outros }\end{array}$ & & \\
\hline $\begin{array}{l}\text { 19) Quando precisa de } \\
\text { alguma planta para } \\
\text { fazer remédio, onde } \\
\text { consegue }\end{array}$ & $\begin{array}{l}\text { ( ) } \\
\text { No próprio } \\
\text { quintal }\end{array}$ & $\begin{array}{c}\text { ( ) } \\
\text { No quintal dos } \\
\text { vizinhos ou } \\
\text { parentes }\end{array}$ & $\begin{array}{l}(\mathrm{)}) \\
\text { No mato }\end{array}$ & & \\
\hline $\begin{array}{l}20) \text { com que } \\
\text { frequência ouve falar } \\
\text { sobre uso de plantas } \\
\text { medicinais }\end{array}$ & $\begin{array}{c}(.) \\
\text { Sempre }\end{array}$ & $\begin{array}{l}\text { ( ) } \\
\text { Pouco }\end{array}$ & $\begin{array}{l}\text { ( ) } \\
\text { Nunca }\end{array}$ & & \\
\hline
\end{tabular}

